\title{
ENGINEERS-IN-RESIDENCE - A BRIDGE TO THE FUTURE
}

\author{
J.M. Symonds, P.Eng and Ron Britton, P.Eng. \\ Faculty of Engineering, University of Manitoba \\ mal_symonds@umanitoba.ca and ron_britton@umanitoba.ca
}

\begin{abstract}
The rapid pace of new technology development has influenced both engineering education and engineering students. It is becoming evident that the education is becoming deficient in addressing new subject matter and industry required skills while attempting to maintain the basic, core engineering fundamentals. Students are also falling behind in their ability to understand and implement these fundamentals. New, integrated approaches, in the real world context, are required to address these curriculum deficiencies in innovative and cost-effective ways.
\end{abstract}

Keywords: engineering education, industry standards, engineering fundamentals, transition to work, soft skills.

\section{INTRODUCTION}

The concept of Engineers-in-Residence originated in 2000 during the development of a proposal for submission to the Natural Sciences and Engineering Research Council (NSERC) for a Chair in Design Engineering at the University of Manitoba in Winnipeg. It had become obvious that engineering students were not obtaining many of the appropriate skills within their academic studies to be able to transition smoothly into the commercial world. While there were some capstone design courses in which students undertook design projects in response to industry problems and programs, industry contact was minimal and standard industry practices were not necessarily followed. The NSERC Chairs in Design Engineering program suggested that a theme be introduced into the engineering academic curriculum whereby students are taught industry skills in the context of academic study. At the University of Manitoba we decided to seek the necessary in-depth industry expertise, and to add to teaching resource levels, by recruiting retired engineers as Engineers-in-Residence.

\section{THE MANITOBA V ISION}

The Natural Sciences and Engineering Research Council (NSERC) Chairs in Design Engineering is an initiative that encourages applicants to seek ways in which to increase design emphasis in engineering undergraduate programs and to increase the visibility of design, on and off campus. NSERC is an agency of the Canadian government that funds research at universities and in industry across Canada. The University of Manitoba Chair is one of an original group of five Chairs that were established in January, 2001. There have been, or are now, more than a dozen such Chairs across Canada, each with slightly different objectives. The original $\mathrm{U}$ of $\mathrm{M}$ Chair objective, operating under the NSERC definition that "Design engineering is concerned with the design and development of new and improved products, processes, and technologies that satisfy specified requirements in an effective and efficient manner", was to increase the numbers of graduate engineers who have the skills required by future employers. In order to accomplish this goal, NSERC and the $U$ of $M$ emphasize 1. increased productivity and innovation in design research, design practices, and design education; 2, establishing productive and effective collaborations between the Chair, industry, and other design faculties and experts across Canada; and 3 . increasing the awareness and appreciation in the community of all aspects of design engineering.

The 2001 Design Chair at the University of Manitoba had a mandate to facilitate design education without undermining technical/academic education. One of the consistent problems with introducing new concepts into engineering education is to ensure that the basic technical knowledge required by all engineers is not compromised. There is a constant debate over teaching the "traditional and basic" engineering knowledge and introducing any new technology or methodology. This fact is especially evident in the balance (or lack thereof) between factual based knowledge and experiential based knowledge. Today's engineering students, by and large, are much more comfortable with theory than they are with "hands on" skills and physical "know how". The Faculty of Engineering at the $\mathrm{U}$ of $\mathrm{M}$ was aware of this issue but, since there was "no room" in the curriculum and limited expertise in the academic staff to implement any programs to rectify the situation, it fell to the Chair to introduce programs that would give the students the "real life" experience that they would require in their subsequent professional lives in industry. 
In addition to introducing design education into the curriculum, the Chair also had the task of trying to make engineering design "respectable" and to provide strong, viable, and workable links to the industrial world, outside of academia.

\subsection{Engineers-in-Residence (EIR's)}

Engineers-in-Residence is a concept developed during Ron Britton's term as Associate Dean (Design Education) in the Faculty of Engineering at the University of Manitoba. The initial idea was to seek out engineers who had spent their careers in design in industry or government, who had retired, and who had the aptitude and ambition to return some of their knowledge and expertise to the profession that had given them their livelihood. A fundamental administrative requirement was that all EIRs must be licensed as professional engineers. As it turned out, this was a workable model and, over the ten year tenure of the Chair to Develop "Design-Ready" Engineers, seven engineers from separate disciplines became involved.

There have been Engineers-in-Residence associated with all of the engineering programs at the $U$ of $M$. Typically, they fit the original concept having retired after extended industry design experience. Once they were appointed as Engineers-in-Residence they were provided with furnished and "equipped" office space on campus and were expected to spend at least $50 \%$ of their time "in residence". Their in-house availability and freedom from structured responsibilities allowed them to become directly (face-to-face) involved with both students and staff . After 10 years of experience in this program, the Engineers-in-Residence have become more and more integrated into the academic programs and are recognized by the academic staff as reliable, available, and valuable resources related to teaching, research, and off-campus connections. The students have come to realize the value of the "different" knowledge these engineers possess. Students are also very appreciative of the industry contacts that the Engineers-in-Residence bring to the campus. In essence, they are now looked upon as assets who support the education process, not potential competition for academic positions.

On campus the EIR's have provided industry practice input to relevant courses, taught courses in design and other areas within their industrial experience, mentored students in team design projects and theses, provided Faculty Advisor services to numerous student technical societies, with specific emphasis on design competitions, and aided in introducing engineering legislation and the professional engineering societies to students. In addition to on campus activities, EIR's have provided "insider" contacts with industry and government which have helped the Engineering faculty and students to broaden their experience, their research resources, and their teaching and learning capabilities. They have also brought a fresh approach to the learning experience and to the students needs by allowing students to experience industrial and governmental practices while learning the theory behind those practices.

Since EIR's have been contributing to courses within the various programs, there has been an apparent benefit of a general increase in student perceived credibility of the course content. The EIR's have been able to put the academic subjects and concepts into the real world context and have provided many examples of the applications of the theories. This has had the spin off benefit of making the theory more important, relevant, and enjoyable for the students and has increased their apparent performance; although there has been no attempt to confirm this observation to date.

\subsection{Design Chair Activities}

The success of the Engineer-in-Residence program cannot be distinguished from the overall conduct of the Design Chair activities. EIR's would not be able to operate effectively if it was not for the context, infrastructure, and administration provided by the Chair. Given that industry experience is much broader than academically structured departmental programs, the EIR's require the freedom of a non-departmental base of operations to fully realize their potential.

One of the first engineering curriculum undertakings of the Chair was to rework and deliver a first year design course that incorporated industry design practices such as teamwork, problem solving, and communication skills. In addition, the course provided an exposure to the legal structure of the engineering profession. All students registered in this class were given the opportunity to become Student Members of the Association of Professional Engineers and Geoscientists of Manitoba (APEGM) at no cost. All students were required to write the Professional Practice exam; a requirement of the APEGM as a first step in the registration process in Manitoba. Clearly, EIR participation in the delivery of this course was/is a significant asset.

The fourth year capstone design programs in Mechanical Engineering and Biosystems Engineering were modified to increase contact with industry. This has been facilitated through an EIR managed, and Design Group facilitated, program called $U$ of $M$ IDEA. Capstone projects suitable for groups of five or six students are actively pursued on a year round basis. Project costs, industry supervision requirements, and contract conditions are consistent across the two departments. An undergraduate student is employed to deal with the maintenance of files and day-to-day contacts, but the industry "friendly" process is directly linked to the EIR supervision. 
Capstone design in Civil Engineering is based on larger teams and a single project. Their requirements were/are not met through $\mathrm{U}$ of M IDEA. However, over the past five years, an EIR, seconded from a major consulting firm, has taken full responsibility for delivery of the course.

Another Chair administered program that EIR's have participated in is the Internationally-Educated Engineers Qualification Program (IEEQ). This is a program that addresses two major qualifications for newly immigrated engineers to become registered as a Professional Engineers in Manitoba: academic qualification and acceptable engineering work experience. The IEEQ Program is an alternative process to meeting the APEGM requirements for academic qualification that allows the candidate to complete the requirements in a controlled and professional environment. It is conducted under the guidance of the profession but it uses academic resources. EIR's, in this context, provide some academic input but, more importantly, provide background for the immigrant engineers in the professional and social conduct of engineering in Manitoba and Canada. This greatly eases their transition to the Professional Engineering society.

Early in the Chair's mandate, monthly Design Colloquia were introduced. These colloquia featured top local engineers and academics who gave presentations on pertinent and topical technical subjects in an informal luncheon format during the fall and spring terms. These events became excellent opportunities for industry and academic personnel to meet and discuss issues of mutual interest. In an important extension of the local colloquia, high profile speakers from the international engineering community have been engaged and have presented talks both on campus and off. While the "free lunch" component of the process eventually caused the colloquium process to collapse, it was an important beginning in extending the local engineering vista beyond parochial bounds. The presence of EIR's among the "academic" audience was critical in building community links.

A unique, and unexpected, benefit of our EIR program has been the growth of the $U$ of M SAE Student Branch. Early in the Design Chair program, Faculty Advisor responsibilities passed from an academic responsibility to the first EIR. Since then, in no small part due to the industry style approach adopted for Branch operations, it has grown to be the second largest student SAE Branch in the world. They now compete in four different SAE international competitions. Support from industry and government has grown significantly and the teams have become serious competitors as opposed to regular participants.

Communication of intent and accomplishments was recognized as a critical component of the Chair and the
EIR initiatives. This was facilitated by appointing a Public Relations Coordinator. Initially a half-time position in the Design Chair office, it has grown to a full-time position that is now a part of the Dean's office.

\subsection{Appointments and Finance}

EIR appointments are made under an "Excluded Professional" classification within the Human Resources structure at the University of Manitoba. This provides the flexibility necessary to accommodate these "unusual" academic positions. Every EIR is also given academic status to distinguish them from "sessional" instructors. They are, in effect, "special academics", housed in, and supported by, the Faculty.

Initially EIR appointments were financed using NSERC Design Chair funds. However, as understanding of the program grew in industry and the provincial government, various other resources became available. The most notable initiative to date has been the creation of the Manitoba Aerospace Engineering Liaison Group. In 2005, three companies, Bristol Aerospace, Boeing, Standard Aero, and the provincially funded Manitoba Aerospace Human Resource Council, entered into a six year memorandum of understanding with the Faculty of Engineering. Each of the four partners provided the Faculty with $\$ 20,000$ annually to support the "Aerospace" EIR, who became the contact person for the Group. While the original MOU focused solely on undergraduate education, the relationship has matured to include annual research requirements/capabilities meetings. The Aerospace MOU was renewed in 2011 for a further six years.

Under the new 2012 approved Design Chair's mandate, the Aerospace MOU model is being explored with other industry groups. As these agreements are finalized, EIR's with specific industry experience will be recruited.

\section{IN CONCLUSION}

Engineers-in-Residence have been a main focal point of the NSERC Chair in Design Engineering at the University of Manitoba. Their in-depth industry expertise and the teaching support they provide have been pivotal in having them accepted into the Engineering Faculty and assisting in the expansion of the design process into the curriculum. Their prior experience equips them to communicate industry's needs and expectations to the academic community. Conversely, their more recently acquired academic experience equips them to explain oncampus needs and limitations to their former colleagues in industry. 